\title{
O contexto social da obra de Ellen Meiksins Wood e a busca por sistematizar uma teoria de classes
}

\author{
Jefferson Ferreira do Nascimento ${ }^{1}$
}

\begin{abstract}
Resumo: O artigo resgata a proposta de Ellen Wood sobre a necessidade de sistematizar uma teoria sobre classes que embase uma renovação do materialismo histórico. Wood pretende em sua renovação embasar a luta pela Democracia Substantiva em que esteja ao alcance do poder do povo não só os ritos que desembocam em uma representação política, mas também a real possibilidade de isegoria, de autodeterminação dos produtores, mediante a "liberdade de livre associação (sic)". Tal intento só pode ocorrer a partir da organização da classe operária, de uma classe como sujeito histórico, para a luta de classes contra os apropriadores amparados pelo Poder Estatal. Para isto, o artigo resgata dados biográficos, o ideal humano e o contexto social da produção de Ellen Wood para compreender a especificidade histórica das suas ideias. Com isso, explica-se o motivo pelo qual a autora entende que a concepção de classe que atende ao empreendimento é a concepção formulada pelo historiador britânico E. P. Thompson.
\end{abstract}

Palavras-chave: Democracia; Luta de Classes; Teoria Política.

\section{The social context of Ellen Wood's work and the quest to systematize a class theory}

\begin{abstract}
The article rescues Ellen Wood's proposal on the need to systematize a theory of classes that embodies a renewal of historical materialism. Wood intends in its renewal to support the struggle for Substantive Democracy in which it is within the reach of the people's power not only the rites that lead to a political representation, but the real possibility of isegoria, of self-determination of the producers, through the "freedom of free association". Such an attempt can only occur from the organization of the working class, from a class as a historical subject, to the class struggle against the appropriators supported by the State Power. For this, the article retrieves biographical data, the human ideal and the social context of Ellen Wood's production to understand the historical specificity of her ideas. This explains the reason why the author understands that the conception of class that serves the enterprise is the conception formulated by the British historian E. P. Thompson.
\end{abstract}

Keywords: Democracy; Class Struggle; Political Theory.

\footnotetext{
1 Doutorando em Ciência Política na UFSCar, Mestre em Ciências Sociais pela UNIOESTE, graduado em Ciências Sociais com Bacharelado em Sociologia e Ciência Política e Licenciatura em Ciências Sociais na Unicamp. É professor no IFSPCampus Sertãozinho. É membro do NEPPLA (Núcleo de Estudos dos Partidos Latino-Americanos).
} 


\section{Introdução}

Este artigo resgata a proposta de Ellen Wood sobre a necessidade de sistematizar uma teoria sobre classes que embase uma renovação do materialismo histórico. Por renovação, entende-se a pretensão de Wood em atualizar as categorias marxistas para fomentar a crítica e embasar a ação a fim de enfrentar a totalidade sistêmica do capitalismo. Um sistema cuja historicidade costuma ser ignorada, como se fosse um dado da natureza e, portanto, significasse o "fim da História". Wood pretende em sua renovação embasar a luta pela Democracia Substantiva ${ }^{2}$ em que esteja ao alcance do poder do povo não só os ritos que desembocam em uma representação política, mas também a real possibilidade de isegoria, de autodeterminação dos produtores, mediante a "liberdade de livre associação (sic)". Tal intento só pode ocorrer a partir da organização da classe operária, de uma classe como sujeito histórico, para a luta de classes contra os apropriadores amparados pelo Poder Estatal, tal como está formatado. Assim:

[...] a questão consiste em ter uma concepção de classe que nos convide a descobrir como as situações objetivas da classe moldam realmente a realidade social e não simplesmente afirmar e reafirmar a proposição tautológica de que "classe = relação com meios de produção". O conceito de classe como relação e processo enfatiza que as relações objetivas com os meios de produção são significativas na medida em que estabelecem antagonismos e geram conflitos e lutas; que estes conflitos e lutas moldam a experiência social "em formas de classe", inclusive quando não se expressam em consciência de classe e formações claramente visíveis; e que através do tempo podemos discernir como estas relações impõem sua lógica, seu esquema, nos processos sociais. As concepções de classe puramente "estruturais" não nos exigem examinar as formas como a classe impõe realmente sua lógica, posto que as classes estão simplesmente aí por definição (WOOD, 1983, s/p., tradução nossa).

Para isto, o artigo resgata dados biográficos, o ideal humano e o contexto social da produção de Ellen Wood para compreender a especificidade histórica das suas ideias. Ou seja, segue a argumentação de que a teoria política é um produto histórico, um "exercício de persuasão", um discurso e uma argumentação fundamentados por algum tipo de verdade "sobre os problemas colocados pela vida política” e não só pela filosofia (WOOD, 2011a, p.11-13). Afinal:

Toda civilização complexa, com um estado e uma classe dirigente organizada, deve gerar algum tipo de reflexão sobre as relações entre os dirigentes e os dirigidos, entre os que mandam e os que obedecem, entre ordenar e obedecer. Tanto em forma de filosofia sistemática ou em uma forma poética, como em forma de uma parábola ou um provérbio, a esta reflexão podemos chamar, tanto nas tradições orais como nas culturas escritas, de pensamento político [...] Os gregos, para o bem ou para o mal, inventaram um modo próprio e distintivo do que significa teoria política: a interrogação sistemática e analítica (cheia de definições laboriosamente construídas) dos princípios políticos; a aplicação da razão crítica à interrogação de seus fundamentos, e a legitimidade das normas morais e dos princípios do direito político (WOOD, 2011a, p.13-14, grifo da autora).

Conforme veremos a seguir, a concepção de classe expressa acima é a concepção formulada pelo historiador britânico E. P. Thompson. Para Ellen Wood, há críticas a Thompson porque o historiador britânico não conceitua classe com base exclusivamente em termos estruturais, por isso, seu conceito não é aplicável "onde não se pode discernir uma consciência de classe" (WOOD, 1983, s/p., tradução nossa). Por um lado, o próprio Thompson adverte que "classe traz consigo a noção de relação histórica" e que essa relação histórica "é algo fluído que escapa à análise se tentarmos imobilizá-la num dado momento",

\footnotetext{
2 Por Democracia Substantiva, Ellen Wood define: “o governo pelo povo ou pelo poder do povo”, de modo que seja possível a "reversão do governo de classe, em que o demos, o homem comum, desafia a dominação dos ricos"2. Dito isto, Wood reafirma que "a crítica original do capitalismo" deve ser realizada por sua antítese, o socialismo. Porém, tal empreendimento, exige "uma crítica não apenas do capitalismo ou da economia política, mas também das oposiçoes existentes, o que implicou o exame crítico da própria tradição socialista". Esse "exame" visa tornar a ideia socialista em "um programa político baseado nas condições históricas do capitalismo". Por isto, ainda que o ponto de orientação da autora seja o socialismo, "a aspiração à democracia" serve como um "tema unificador entre as várias oposições fragmentadas" (WOOD, 2011b, p. 21).
} 
comportando, inclusive, o risco de anacronismo (THOMPSON, 1987, p. 9-10). Por outro lado, para E. Wood, esta forma de análise que considera relação e processo histórico é importante justamente por permitir a análise dos casos onde a consciência de classe não aparece claramente e, por isso, a classe não apresenta contornos nítidos.

\section{Contextualizando Ellen Meiksins Wood}

De acordo com a consideração de Florestan Fernandes (2012), “A Ideologia Alemã recolhe e sublima a experiência revolucionária concreta, acumulada por Marx e Engels de fins de 1843 em diante. [...] A atividade prática abriu-lhes novas perspectivas de observação direta da realidade" (FERNANDES, 2012, p. 53). Ou seja, tal formulação está em consonância com as proposições de Neal Wood, segundo o qual cada texto clássico de teoria política constitui uma reflexão sobre seu tempo, que versa sobre a natureza da sociedade em que foi produzido e, como desdobramento, do fato de que um "teórico político, muitas vezes, adota uma posição partidária no conflito de seu tempo, assumindo algum tipo de compromisso básico com uma determinada posição social e política" (WOOD, 2002, p. 45, tradução nossa). Afinal, o material de Marx são indivíduos reais, suas ações e as suas condições de vida.

Assim, para reafirmar a importância do marxismo para as análises políticas, notadamente a teoria política, é fundamental verificar em que medida a obra sinaliza o engajamento do autor em um conflito de seu tempo. Para tanto, é fundamental uma ferramenta analítica que enfrente o anacronismo. Como o autor está situado em um conflito real, devemos explicar os motivos para ter defendido certos interesses e compreender se o seu engajamento prático influenciou sua obra. Afinal, para Neal Wood, uma teoria política consiste na tradução do ideal bumano em prescrições sociais e políticas, visando resolver o problema de como as instituições e a ação política contribuem para realização do ideal de justiça assumido e defendido pelo autor (CARDOSO; SILVA; NERES, 2016; WOOD, 2002). De acordo com Ellen Wood, compreender o ideal humano proposto por um determinado autor é a chave para entender a sua posição acerca dos conflitos de sua época (WOOD, 2011a).

Para atingir os objetivos enunciados, faremos uma análise bibliográfica, resgatando o debate entre Ellen Wood e Thompson com outros Marxistas acerca do conceito de classe. Esse resgaste objetiva contribuir com a elaboração de uma teoria de classe que fundamente a renovação do materialismo histórico proposto por Ellen Wood, isto é, partindo do entendimento de que a teoria política é um produto histórico. O propósito é superar a "divisão estéril" da ciência política entre a "ciência política real", que supostamente é lida "com os fatos da vida política como eles são" e a "teoria", que reflete "não sobre o que é, mas sobre o que deveria ser" (WOOD, 2011a, p. 17, grifo da autora, tradução nossa). O entendimento fundante para este trabalho é que os pensadores clássicos se comprometeram e se engajaram com problemas reais do contexto em que viveram sem serem propagandistas. Assim:

Os textos destes pensadores são muitos diferentes entre si, mas tem alguns pontos em comum. Embora, em algumas ocasiões, analisam o estado como é, seu principal empenho consiste em analisa-lo de maneira crítica e prescritiva, pois todos eles concebem como deveria ser a ordenação justa e adequada da sociedade e do governo. E aquilo que, frequentemente, se concebe como "justo" se embasa em certa concepção de justiça e de vida moralmente boa, mas também pode proceder algumas reflexões práticas sobre aquilo que é necessário para manter a paz, a segurança e o bem-estar material (WOOD, 2011a, p. 15, tradução minha).

A teoria política é um "exercício de persuasão", é um discurso e uma argumentação fundamentados por algum tipo de verdade, ancorado em tradições filosóficas e em problemas colocados pela vida política e, portanto, suas teorias se diferenciam na mesma medida em que os problemas enfrentados foram diferentes. Para os clássicos da política, quem e como deveriam governar eram questões centrais que se relacionavam com as "perguntas fundamentais" a serem respondidas em suas obras (WOOD, 2011a). 


\section{Dados Biográficos}

A trajetória familiar e a formação de Ellen Meiksins Wood, nascida no ano de 1942 em Nova York, ocupam papel fundamental para compreensão de sua produção. Afinal, sua produção teórica mira uma práxis, seus embates acadêmicos caminharam pari passu com o empreendimento de fomentar teoricamente uma prática que supere as lutas fragmentárias. Por isto, o foco dessa seção será contextualizar as mudanças ocorridas na Letônia, que culminaram na migração de seus pais para os Estados Unidos.

A Letônia se tornou independente da Rússia em 1918, efeito direto da ascensão dos bolcheviques ao poder. A população judaica - origem de Ellen Wood - não chegou a constituir um grupo homogêneo em termos socioeconômicos. Havia importantes diferenças econômicas e sociais entre eles. Até mesmo religiosamente havia influência das tradições comunais e populares do judaísmo russo. Porém, favorecido pela proximidade da Prússia Oriental - parte da Alemanha -, havia também a influência do judaísmo da Europa Ocidental, o que tem reflexos políticos. Os judeus se organizavam em diferentes partidos, com ideologias muito diferentes entre si (DRIBINS, 2014).

Tiveram representação na Assembleia Constituinte e no Parlamento da Primeira República Letã (1920-1931) as seguintes organizações partidárias judaicas: Sionistas, Nacionais Democratas, Agudat Yisrael - partido conservador de maioria de judeus ortodoxos - e Bund - partido socialista judeu. Mesmo com ascensão de Karlis Ulmanis como ditador em 1931, a situação dos judeus era relativamente menos complicada do que nos países vizinhos: ele concebia a Letônia como um Estado de caráter multinacional. A Letônia não aprovou nenhuma lei racista ou antissemita antes da guerra e recebeu refugiados judeus da Alemanha e da Áustria no fim da década de 1930. Além disso, o movimento ultradireitista com posições antissemitas era ilegal antes da guerra (SNEIDERE, 2005).

A situação dos judeus na Letônia muda a partir da ocupação soviética (1940-1941) e da ocupação nazista (1941-1944). Junto com as lideranças políticas letãs, lideranças civis e políticas dos judeus locais foram presas em agosto de 1940. Em 1941, milhares de letões de todas as etnias foram deportados para a Sibéria, para Ásia Central e outras regiões da União Soviética. Em torno de 12,5\% dos deportados letões eram judeus, enquanto a população judaica correspondia a 4,5 a $5 \%$ da população letã. A prisão das lideranças judaicas desmobilizou os judeus letões (DRIBINS, 2014; SNEIDERE, 2005).

Porém, a situação da população judaica na Letônia se agrava a partir do ano de 1941. Chega ao país o Einsatzgruppe A, formado por 990 homens da Gestapo e da Waffen SS. Esse grupo encontrou apoio de grupos de ultradireita com orientação antissemita, que estava na clandestinidade antes de 1939 e que fugiram ou foram deportados no início da ocupação soviética. O objetivo era exterminar judeus e colaboradores do regime soviético. De uma população judaica de aproximadamente 90 mil, apenas 15 mil judeus conseguiram fugir para a União Soviética. Estima-se que aproximadamente 35 mil judeus que permaneceram na Letônia foram mortos em outubro de 1941, quando a ocupação nazista se consolidava no país (DRIBINS, 2014).

As informações sobre Ellen Meiksins Wood apontam que ela nasceu cerca de um ano após a chegada de seus pais aos Estados Unidos e que seu pai teria sido um membro do Bund até 1940. A vinda para o continente americano é, provavelmente, consequência desse período de maior tensão para os judeus. Cruzando informações, podemos concluir que seu pai militou no Bund até a prisão de lideranças políticas e civis dos judeus letões pelos soviéticos, a partir de agosto de 1940. Tais prisões não foram exclusivamente de judeus na Letônia, mas foram suficientes para desmobilizar a comunidade judaica, tornando-a ainda mais vulnerável aos ataques do Einsatzgruppe $A$ e da extrema direita local, que retornou ao país em 1941. A chegada da família Meiksins nos Estados Unidos ocorre em 1941, mas não é possível afirmar se a busca pelo refúgio na América se dá no final da invasão soviética ou como fuga da invasão nazista, que provocou o Holocausto Letão. A despeito dessa imprecisão, as informações nos permitem, com segurança, relacionar sua história familiar com as tensões dos regimes totalitários e, sobretudo, com os impactos do antissemitismo, estimulado pelo regime nazista (DRIBINS, 2014; MCNALLY, 2016). 
Além dessa história familiar marcada, negativamente, pelas ações militares, tanto do regime stalinista como do nazista, a formação acadêmica de Ellen Meiksins Wood ocorre entre fins dos anos 1950 e 1970, obtendo, em 1962, o bacharelado em Línguas Eslavas na Universidade da Califórnia, em Berkeley e, em 1970, o PbD em Ciência Política na Universidade da Califórnia, em Los Angeles.

Esse período da história foi marcado pela tensão da Guerra Fria, sobretudo a Crise dos Mísseis e a ampliação do arsenal nuclear como recurso para a corrida armamentista. Além disso, o período de sua formação foi marcado pelo fortalecimento de uma série de movimentos, como os contraculturais jovens - hippies, por exemplo -, o pacifista, o feminista e o negro. Portanto, uma época de tensão e de questionamentos, inclusive, ao modelo socialista soviético e ao capitalismo, encabeçado pelos Estados Unidos, e de intensificação das lutas pelos direitos civis, tanto dos negros como das mulheres, que voltaram a sofrer ${ }^{3}$ com as mudanças culturais e econômicas do pós-guerra (MCNALLY, 2016; HARVEY, 2012). Formou-se em um momento, segundo David Harvey, de fortalecimento de uma nova esquerda que se via como "uma força cultural e político-econômico" e que, como consequência de sua luta também contra a velha esquerda, "tendia a abandonar a sua fé tanto no proletariado como instrumento de mudança progressista como no materialismo histórico como método de análise" (HARVEY, 2012, p. 319-321).

Ellen Meiksins, mulher de origem judaica, nascida em uma família de classe média, filha de um militante socialista, empenhou-se na renovação do materialismo histórico, trazendo consigo a importância da incorporação da democracia - a Democracia Substantiva -, como forma política indispensável para o modo de produção socialista. A crítica ao stalinismo e às expressões acadêmicas que continuavam a ortodoxia stalinista parece ser o referencial teórico da sua preocupação com a ascensão de governos totalitários, que marcou negativamente a trajetória de sua família, ainda na Letônia. Como mulher e judia reforçou o papel da isegoria como parte indispensável da Democracia Substantiva (WOOD, 2011b).

Desse modo, apesar de enxergar as lutas identitárias como "insuficientes" para combater a exploração do trabalho, sua exigência pelo direito de igualdade de fala e proposição parece ressaltar a importância da incorporação de grupos historicamente discriminados. Porém, sempre é preciso enfatizar a centralidade que Ellen Wood confere à classe como elemento unificador da experiência. E, como pesquisadora e professora universitária, passou a defender a importância da experiência para a formação consciente de classe, reagindo aos desdobramentos históricos provocados por concepções marxistas que afirmavam a centralidade do partido e/ou do intelectual como condutor de um operariado sem condições de compreender a própria realidade. O que estava em jogo para Ellen Wood é ressaltar que, ainda que o partido e/ou os intelectuais tenham papel importante para a luta, estes são as ferramentas e não a finalidade. São instrumentos para a compreensão da realidade e não podem ser vistos como portadores de uma consciência ideal que será distribuída aos trabalhadores. Num resgate de Thompson, a autora defendeu a importância da luta a partir da base e, nessa luta, o partido e/ou intelectual podem estimular a reflexão sobre a experiência, mas jamais substituí-la por um programa e/ou reflexões prontas. Ellen Wood, nascida em uma família afetada por regimes que mistificavam o partido e crescida em um ambiente em que a fragmentação do mundo do trabalho teve como referencial análises teóricas fragmentárias, defende a importância do marxismo como a teoria capaz de compreender a totalidade e a importância de "recolocar" a classe no centro da luta política, como unificadora da experiência e cujo partido e/ou intelectuais devem estar a serviço - e não o contrário (WOOD, 2011b).

\footnotetext{
3 Afirma-se "voltaram a sofrer", pois nos Estados Unidos as mulheres estavam se inserindo no mercado de trabalho na primeira metade do século XX, sobretudo durante a Segunda Guerra Mundial. Não há nenhuma intenção de afirmar que, antes dos anos 1960, a emancipação feminina estava concluída. Obviamente, o machismo ainda era forte. Porém, no período pós-Segunda Guerra Mundial, sobretudo nos “anos de ouro” (1945-1970), o modelo de família patriarcal volta a ser exaltado com muita força, inclusive nos meios de comunicação.
} 


\section{Ideal Humano}

O ideal humano defendido por Ellen Wood guarda relação com o ideal humano de Marx, ainda que não seja exatamente o mesmo. O ideal humano para Marx e Engels seria, então, de acordo com Neal Wood, "a realização do potencial físico e mental do indivíduo e na efetivação desses poderes criativos dentro de um contexto social radicalmente transformado que acabaria com a alienação humana e a exploração do homem pelo homem" (WOOD, 2002, p.55, tradução minha).

Ellen Wood conserva como ideal a realização do potencial físico e mental do indivíduo, reafirma a efetivação desses poderes criativos, mas o contexto social radicalmente transformado que acabaria com a alienação bumana é tanto a superação da exploração do homem pelo homem quanto - e não menos importante - o reconhecimento de uma forma política democrática, substancialmente democrática. E. Wood rejeita a democracia representativa burguesa e liberal, mas não nega a importância das liberdades civis afirmadas pelos ideais burgueses. Assim, superar a realidade atual implica uma oposição dialética à totalidade de componentes do real cujo resultado é uma síntese que absorve a essência do que foi confrontado em novas formas e condições (WOOD, 1983; WOOD, 1998; WOOD, 2011b).

Para conseguir essa transformação, o agente político, cuja realidade revela a disposição e possibilidade para o enfrentamento, é a classe operária, e cuja formação consciente para a luta de classes nasça da capacidade de reflexão dos trabalhadores para compreender e analisar o compartilhamento de uma dada situação e de reagir conscientemente aos interesses que constituem obstáculos à superação da realidade marcada pela exploração do trabalho e pela submissão política.

O abismo entre a realidade e o ideal humano é grande, mas esse ideal é possível a partir da atuação da classe como sujeito histórico. A partir da atuação da classe operária, visando à instituição da Democracia Substantiva, todos poderiam experimentar uma realidade em que haja isegoria, autodeterminação dos produtores e a "liberdade de livre associação (sic)". Sendo assim, na Democracia Substantiva, governantes e governados coincidem, tendo como referência prático-teórica os fundamentos da democracia ateniense e o papel central dos campesinos (WOOD, 1983; WOOD, 1998; WOOD, 2011b).

\section{O Contexto Social de sua Produção}

A formação de Ellen Wood, entre os anos 1950 e 1970, quando obtém o PhD em Ciência Política, ocorre em um período de declínio do Fordismo e do Keynesianismo, o que incluiu o abandono do Welfare State. Tal período de modificação, identificado como reestruturação produtiva, marcou o enfraquecimento político da classe operária como consequência da desmobilização dos trabalhadores enquanto classe. Portanto, sua formação, pesquisa e produção intelectual ocorrem em um período de mudança no mundo do trabalho, na política econômica e na forma de organização do Estado. David Harvey nos ajuda pensar essa questão:

[...] o período de 1965 a 1973 tornou cada vez mais evidente a incapacidade do fordismo e do keynesianismo de conter as contradições inerentes ao capitalismo. Na superfície, essas dificuldades podem ser apreendidas por uma palavra: rigidez. Havia problemas com a rigidez dos investimentos de capital fixo de larga escala e de longo prazo em sistemas de produção em massa que impediam muita flexibilidade de planejamento e presumiam crescimento estável em mercados de consumo invariantes. Havia problema de rigidez nos mercados, na alocação e nos contratos de trabalho (especialmente no chamado setor 'monopolista'). E toda tentativa de superar esses problemas de rigidez encontrava a força aparentemente invencível do poder profundamente entrincheirado da classe trabalhadora - o que explica as ondas de greve e os problemas trabalhistas do período 1968-1972 (HARVEY, 2012, p. 135). 
A análise de Harvey nos dá um sentido mais profundo para as seguintes transformações. Estava em curso a Crise do Petróleo, que se inicia em 1965, mas atinge contornos mais graves no Primeiro (19731974) e no Segundo (1979-1981) Choque do Petróleo. Como consequência geopolítica, ocorre a intensificação da disputa pelo Oriente Médio entre Estados Unidos e União Soviética. Na economia, a doutrina neoliberal ganhava terreno, sobretudo com Ronald Reagan, como presidente estadunidense, e com Margareth Thatcher, como premiê do Reino Unido. Tais mudanças ressaltavam objetivamente o grau de hegemonia da burguesia e do capital financeiro e especulativo em detrimento de uma vulnerabilização política dos trabalhadores, partindo das economias centrais - que Wood vivencia diretamente - e atingindo as economias periféricas, como a Crise da Dívida enfrentada pelos países latinoamericanos.

Esses fatores estão associados à gradual substituição do modelo fordista/taylorista pela acumulação flexível, cujo modelo mais conhecido é o toyotista. Nas palavras de Harvey:

A profunda recessão de 1973, exacerbada pelo choque do petróleo, evidentemente retirou o mundo capitalista do sufocante torpor da 'estagflação' (estagnação da produção de bens e alta inflação de preços) e pôs em movimento um conjunto de processos que solaparam o compromisso fordista. Em consequência, as décadas de 70 e 80 foram um conturbado período de reestruturação econômica e de reajustamento social e político [...] A acumulação flexível envolve rápidas mudanças dos padrões do desenvolvimento desigual, tanto entre setores como entre regiões geográficas, criando, por exemplo, um vasto movimento no emprego no chamado 'setor de serviços', bem como conjuntos industriais completamente novos em regiões até então subdesenvolvidas (HARVEY, 2012, p. 140).

Essas mudanças impactaram profundamente na organização do movimento trabalhista. O movimento operário, em geral, e as organizações sindicais, em particular, foram atingidos pela flexibilização das relações de trabalho, pelo desemprego estrutural, pela subcontratação, pela diversificação etária e de gênero da força de trabalho, pela redução do emprego industrial, pela possibilidade de deslocamento e segmentação da atividade da empresa, pelas novas formas de gestão de pessoas nas empresas que discursivamente enfatizam a participação na organização e pela mudança do padrão sociocultural, que passa a ser mais individualista que coletivista. Todas essas mudanças colocaram sob intensa pressão os movimentos operários tradicionais e abriram espaço para o Novo Sindicalismo, baseado na concepção estadunidense dos Novos Movimentos Sociais (NMS) (SANTANA; RAMALHO, 2010).

Tal concepção resultava do fortalecimento de uma nova esquerda que se via como "uma força cultural e político-econômico" e que, como consequência de sua luta também contra a velha esquerda, "tendia a abandonar a sua fé tanto no proletariado como instrumento de mudança progressista como no materialismo histórico como método de análise" (HARVEY, 2012, p. 319-321).

Somado a isto, temos um novo período de desigualdade, marcado pela vulnerabilidade social e econômica. Nesse período, o instituto da proteção social é suplantado por uma lógica baseada na competitividade, o referencial desse fenômeno é o abandono do Welfare State e o avanço neoliberal. As consequências socioeconômicas dessa mudança foram o aumento das taxas, da pobreza global e da desigualdade social (SANTANA; RAMALHO, 2010).

A queda do Muro de Berlim (1989) e a dissolução da União Soviética - URSS (1991) significaram a consolidação do processo de mundialização da economia, a chamada Globalização Econômica. Essa etapa do capitalismo é marcada pela integração dos mercados mundiais por meio da internacionalização da economia e do capital. Imediatamente após a dissolução da URSS e da Cortina de Ferro, falava-se em uma ordem unipolar, em que os Estados Unidos, como vencedores da Guerra Fria, assumiriam uma posição de astro central, sendo que os demais países e blocos econômicos transitariam em sua órbita, sujeitos a sua influência. Entretanto, a despeito da incontestável posição dos Estados Unidos, tivemos, na verdade, uma ordem multipolar com a ascensão econômica da China, o fortalecimento da União Europeia, a estratégica posição do Japão e dos Tigres Asiáticos e a ascensão dos BRICS - Brasil, Rússia, 
Índia, China e África do Sul. Essa complexificação das relações político-econômicos pode ser simbolizada pela substituição do G8 - grupos das sete maiores economias mundiais, mais a Rússia - pelo G204.

Esse período foi marcado pelo avanço das políticas de austeridade, pela hegemonia neoliberal somente contestada mais diretamente a partir da Crise de 2008 -, que impactam diretamente a vida da classe trabalhadora. A substituição da rede de proteção social por uma lógica individualista, baseada na competitividade; a busca da mais-valia internacional direcionando os empregos industriais em locais menos desenvolvidos, cujas legislações ambiental e trabalhista são mais permissivas; e o desemprego estrutural e a migração dos empregos para o setor de serviços nas economias mais industrializadas desmobilizam, sobremaneira, a classe trabalhadora. Tais transformações estão associadas ao necessário período de reorganização e de redefinição da Esquerda mundial, deixando ainda mais vulneráveis os trabalhadores.

Ellen Wood, então, rejeita abrir mão da viabilidade do materialismo histórico, antes, propõe o desafio de repensar a sua pertinência em uma realidade em que análises fragmentárias de mundo - pósmodernismo, pós-marxismo etc. - ganharam terreno. Se E. P. Thompson morreu quando esse processo se intensificava, Ellen Wood acompanhou a consolidação de uma realidade social e de um posicionamento teórico em que a situação de classe perde espaço para formas de pensamento que advogavam numerosas formas de identificações sociais mais determinantes que a classe. A luta de classes perde terreno, na teoria e na prática política, para intelectuais e movimentos que pensam a mudança social a partir da alteração de hábitos e valores nas sociedades. A identidade permanente de classe é substituída pela efemeridade da convergência de interesses coletivos, e é dialogando e respondendo a esse contexto que o pensamento de Ellen Wood se insere (SARTELLI, 2013).

Em termos intelectuais, junto com Robert Brenner ${ }^{5}$, Wood formula o Marxismo Político ao longo dos anos 1980, que nasce com objetivo expresso de se contrapor ao estruturalismo, aos pós-marxismos, ao marxismo analítico e a outras vertentes, marxistas ou não, que negavam a "possibilidade da política revolucionária" (SARTELLI, 2013, p. 8, tradução nossa). O Marxismo Político tem como principal influência o Grupo de Historiadores do Partido Comunista Britânico, com destaque para Edward Palmer Thompson ${ }^{6}$, visando à recuperação da luta de classes como elemento central da "dinâmica histórica" e, também, do papel central da classe operária na superação do capitalismo em direção ao socialismo (SARTELLI, 2013, p. 8, tradução nossa).

Contudo, como resultado da política soviética, esse grupo de historiadores britânicos sofreu oposição da "nova esquerda", principalmente, a partir do grupo encabeçado por Perry Anderson e Robin Blackburn "reunido em torno da New Left Review". Essa oposição resultou em uma divisão: "alguns, como Hobsbawn, permaneceram fiéis ao PC até muito tarde"; outros se alinharam, de algum modo, à "nova esquerda". Este último é o caso do importante referencial teórico de Ellen Wood, E. P Thompson, que se aproxima da "nova esquerda", ainda que não, inteiramente, sem se afastar por completo das

\footnotetext{
${ }^{4}$ Parte dessas informações pode ser repensada e não refletir a realidade geopolítica atual. Principalmente em relação à grave crise econômica que afetou o Japão e a incerteza em relação aos rumos da União Europeia a partir da saída do Reino Unido (Brexit). Porém, o quadro elaborado se refere ao período dos anos 1990 e início dos anos 2000, relativo ao contexto em que parte da obra de Ellen Wood foi escrita e publicada. Neste contexto, sobretudo com o fraco crescimento econômico dos Estados Unidos e dos países da Zona do Euro, os países emergentes começam a aumentar sua influência geopolítica e econômica. Para ser mais preciso, entre 2000 e 2008, os países emergentes e em desenvolvimento cresceram, em média 6,5\% ao ano, enquanto os países desenvolvidos cresceram 2,3\% ao ano. Nesse período o crescimento médio da economia mundial era de 4,1\% ao ano. Entre 2009 e 2011 a disparidade aumentou: os países emergentes e em desenvolvimento cresceram, em média, 5,5\% ao ano, enquanto os países desenvolvidos cresceram, em média, 0,4\% ao ano. Apesar da desaceleração no crescimento dos países de economia emergente e em desenvolvimento em virtude da crise das commodities, o maior crescimento dos países emergentes e em desenvolvimento em relação aos países desenvolvidos continuou em 2012 (5,1\% contra 1,2\%), em 2013 (5,0\% contra 1,4\%) e em 2014 (4,6\% contra 1,8\%) (BRASIL, 2015, p. 93-95).

5 Historiador norte-americano, que desenvolveu a vertente do Marxismo Político com Ellen Wood. Hoje é diretor do Centro de Teoria Social e História comparada da Universidade da Califórnia (UCLA), editor do jornal Against the Current e membro do comitê editorial da New Left Review.

${ }^{6}$ Além de Thompson, "Eric Hobsbawn, Rodney Hilton, Christopher Hill, George Rudé e outros.” (SARTELLI, 2013, p. 9).
} 
formulações do Grupo de Historiadores do Partido Comunista Britânico (SARTELLI, 2013, p. 8-10, tradução nossa).

Essa posição singular faz de Thompson uma referência no debate contra o althusserianismo e o coloca teoricamente em debate contra Perry Anderson. Sua produção acende um debate sobre "ortodoxia" ou "heterodoxia" no interior do Marxismo, sendo muito influente na produção de Ellen Wood e, por vezes, utilizado pelo "nascente pós-modernismo". O fundamental é que, como influenciada por Thompson, o embate teórico travado por Ellen Wood foi o de oferecer "aportes à reconstrução do materialismo histórico” e não só ser uma destacada thompsoniana (SARTELLI, 2013, p. 11-13, tradução nossa).

Nesse intento de recuperar a centralidade da classe operária e de reconstruir o materialismo histórico, Ellen Wood retoma o mote da crítica de Marx ao cunhar a expressão "Novo Socialismo "Verdadeiro" (NSV). A autora, ainda nos anos 1980, formulava contundente crítica ao chamado "pósmarxismo" que, como um "novo revisionismo", pavimentava o caminho para os pós-modernismos ao "rechaçar a primazia da política de classes e substituí-la pela luta pela democracia", sobretudo a ser conduzida pelos 'Novos Movimentos Sociais'.” (WOOD, 1998, p. 3, tradução nossa). Esse grupo de autores, à época encabeçado por Chantal Mouffe, "Ernesto Laclau, Barry Hindess, Paul Hirst e Gareth Stedman Jones", retirou "a classe trabalhadora de seu lugar central e substituiu antagonismos de classe por divisões ideológicas ou 'discursivas'.” (WOOD, 1998, p. 2, tradução nossa).

A autora reconhece que nesse grupo de autores há uma diversidade de elaborações teóricas com maior ou menor grau de elaboração, pois nem todos os autores se pronunciaram de igual forma ou se comprometeram com os mesmos princípios, porém, é possível reconhecer, em linhas gerais, a seguinte argumentação: a classe operária não produziu um movimento revolucionário, comprovando que não existe uma correlação necessária entre economia e política, não havendo relação privilegiada entre classe operária e socialismo, pois o movimento socialista é, em princípio, independente de classe, ou seja, seria possível construir o socialismo "como uma pluralidade de lutas democráticas", podendo substituir "socialismo" por "democracia radical" (WOOD, 1998).

\section{Especificidade Histórica das Ideias de Ellen Meiksins Wood}

Não restam dúvidas de que Ellen Wood, como teórica, buscava restaurar, no mundo acadêmico, o papel do marxismo como ferramenta analítica e instrumento político de enfrentamento à exploração do homem pelo homem e ao enfraquecimento da condição da cidadania. Ela se incumbia de tal função justamente em um momento político - a falência do socialismo real - e intelectualmente adverso - a ascensão do pós-marxismo e o início do desenvolvimento do pós-modernismo. Seu desafio intelectual consistia em reconstruir um campo que fosse capaz de comprovar que a democracia radical não substituiria o socialismo. Pelo contrário, essa democracia só seria possível substancialmente no modo de produção socialista, em que a participação política garantisse a autodeterminação dos produtores.

Todo esse desafio enfrentado no ambiente acadêmico traz consigo a pretensão de renovar o materialismo histórico para que ele volte a servir como práxis, em reação às lutas fragmentárias, as quais a autora reconhece uma importância, mas, primordialmente, ressalta a insuficiência para a emancipação do homem nos termos de seu ideal humano. Portanto, como parte de seu empreendimento teórico, sua obra trata, primeiramente, da construção - ou reconstrução - do campo, mas sua pretensão não se limita aos debates acadêmicos, uma vez que, a partir da renovação do materialismo histórico, pretende recuperar a centralidade da classe para a luta de classes. 


\section{A entrada de Ellen Wood no debate marxista sobre classes sociais}

Apesar de Poulantzas não fazer uma análise simplificadora da classe e da luta de classes e de ser o mais importante autor da tradição pós-althusseriana, Ellen Wood o classifica como precursor do "Novo Socialismo 'Verdadeiro" (NSV) ou "New 'True' Socialism" (NTS). Para ela, as bases dos tópicos e temas mais importantes do NSV se encontram no trabalho de Nicos Poulantzas. Porém, se E. Wood não o considera um "expoente completamente desenvolvido do NSV", ela o reconhece como notório precursor. Além disto, como Poulantzas foi o principal expoente do pós-althusserianismo, ela acredita que, se tivesse vivido mais, "a lógica de seu trabalho teórico e sua trajetória política alcançaria a posição que seus colegas pós-althusserianos" ocuparam no NSV, nos anos 1980 (WOOD, 1998, p. 25, tradução nossa). Antes de registrar mais precisamente as críticas de Ellen Wood a Poulantzas, passemos a compreender o NSV.

No Manifesto Comunista, ao distinguir sua proposta dos diversos tipos de socialismos existentes, Marx elabora críticas, dentre outros, a teóricos como Bruno e Edgar Bauer e Karl Grun, chamados de "verdadeiros" socialistas ou de socialistas alemães, pois considera que a proposta desses autores abandona a centralidade da luta de classes para a superação do capitalismo. Para Marx, esses teóricos defenderam "não verdadeiras necessidades, mas a 'necessidade da verdade'; não os interesses do proletariado, os interesses do ser humano, do homem que não pertence a nenhuma classe". Esses "verdadeiros" socialistas, considerados como reacionários por Marx, serviram de "arma nas mãos dos governos [ainda no regime absolutista] contra a burguesia alemã” (MARX; ENGELS, 2007, p. 63).

Ellen Wood retoma o mote da crítica de Marx ao cunhar a expressão "Novo Socialismo "Verdadeiro" (NSV), a autora, ainda nos anos 1980, formulava contundente crítica ao chamado "pósmarxismo" que, como um "novo revisionismo", pavimentava o caminho para os pós-modernismos ao rechaçar a luta de classes e substituí-la pela "luta pela democracia", sobretudo a ser conduzida pelos "Novos Movimentos Sociais".

A autora reconhece que nesse grupo há uma diversidade de formulações teóricas com maior ou menor grau de elaboração, pois "nem todos os seus membros se pronunciaram de igual forma ou se comprometeram com os mesmos princípios", porém, é possível reconhecer, em linhas gerais, a seguinte argumentação: a classe operária não produziu um movimento revolucionário, o que comprovaria a inexistência de correlação "entre economia e política [...] [e da] relação privilegiada entre classe operária e socialismo", pois o movimento socialista é, em princípio, independente de classe. Portanto, seria possível construir o socialismo a partir de uma pluralidade de lutas democráticas, podendo substituir "socialismo" por "democracia radical” (WOOD, 1998, p. 2-4, tradução nossa).

Porém, ao se separar de uma classe e se vincular a "coletivos sociais" ou "alianças populares", a "coesão, objetivos, identidade e capacidade para ação coletiva não se originam em interesses e relações sociais específicas, mas são constituídas pela política e ideologia” (WOOD, 1998, p. 5, tradução nossa). Um projeto de transformação social que não coloca a classe no centro não considera:

[...] a posse do poder estratégico e uma capacidade de ação coletiva [...] [e estabelece] [...] a linguagem ou 'discurso' como princípio predominante na esfera social [...] [o que faz convergir] certas correntes pósmarxistas com o pós-estruturalismo [...] dissociando ao máximo ideologia e consciência de qualquer base social ou histórica (WOOD, 1998, p. 5, tradução nossa).

Curiosamente, apesar de defenderem, a partir dos anos 1980, a autonomia da política e da ideologia em relação à classe, alguns desses teóricos se aproximam de Louis Althusser e defendem que “o econômico é o fator determinante em última 'instância', pois determina qual 'instância' será determinante ou dominante". Tal princípio aplicado às classes se traduz na tese de que "algumas

\footnotetext{
${ }^{7}$ Inclusive, o Novo Sindicalismo é baseado na concepção estadunidense dos Novos Movimentos Sociais (NMS), aliado a "nova esquerda" (SANTANA; RAMALHO, 2010, p. 40-43).
} 
condições econômicas determinam que a própria economia será dominante, enquanto outras estabelecem que a política ou ideologia serão 'relativamente' autônomas e dominantes". Sendo mais direto: “certas condições de classe definem que as pessoas estarão sujeitas à necessidade material, enquanto outras permitem maior liberdade intelectual e moral". A rigor, a classe operária tenderia a interesses "economicistas" ou "reformistas" devido aos seus interesses materiais serem mais imediatos (WOOD, 1998, p. 6-7, tradução nossa).

Assim, um conjunto de autores passa, a partir dos anos 1980, a reforçar a tese de que a luta por uma "democracia radical" substituindo o socialismo dependeria de uma "aliança popular", cuja situação de classe não implique interesses materiais imediatos, permitindo maior liberdade intelectual e moral do que o que é possível à classe operária (WOOD, 1998).

Voltemos a Nicos Poulantzas, que, para Ellen Wood, foi possivelmente o principal autor da tradição pós-althusseriana, que buscou, por meio de "suas preocupações filosóficas [...] [compreender] os problemas políticos do socialismo contemporâneo" (WOOD, 1998, p. 25, tradução nossa). Além disso, Poulantzas impressiona pela vasta produção, tendo vista sua morte prematura.

Conforme argumenta Ellen Wood, para o teórico greco-francês "o político e não o econômico" predomina no capitalismo monopolista. Com isso ele pretende afirmar "que as relações de exploração (ainda que sejam 'determinantes em última instância') já não são as que governam.”. O cerne da contribuição de Poulantzas ao NSV está na "transformação crítica na teoria e prática marxista que realiza o eurocomunismo, e constitui seu giro estratégico". Trata-se, mais diretamente, do "deslocamento da oposição principal das relações de classe entre capital e trabalho até as relações políticas entre 'o povo' e a força dominante ou bloco de poder organizado em torno do Estado" (WOOD, 1998, p. 33, tradução nossa). Além disso:

[...] sua crescente aceitação da 'democracia', como um conceito indeterminado que une em seu seio o capitalismo e a democracia socialista em uma continuidade perfeita, obscurece as contradições, os antagonismos e os conflitos de classe que existem entre socialismo e capitalismo. Com isto, Poulantzas está antecipando um dos mais importantes temas do Novo Socialismo "Verdadeiro". Porém, não desenvolveu estes temas até chegar às últimas conclusões, por isso seria muito mais correto não declarálo o maior expoente do NSV, mas seu mais importante antecedente (WOOD, 1998, p. 46, tradução nossa).

Apesar da complexa e importante formulação, a obra de Nicos Poulantzas se distancia de um referencial teórico que possibilite a Democracia Substantiva, pois qualquer projeto emancipatório deve mirar a "desalienação do poder em cada nível da atividade humana, desde o poder criativo do trabalho até o poder político do Estado" (WOOD, 1998, p. 15, grifo da autora, tradução nossa). Para isso, é importante assinalar que pensar a classe operária no centro da transformação social como faz o socialismo revolucionário se baseia em uma análise exaustiva das relações sociais e do poder.

$\mathrm{Na}$ sociedade capitalista, "as relações de produção conformam o centro da vida social e define seu caráter explorador como a raiz da opressão social e política" donde surgem as seguintes formulações: (1) "a classe operária é o grupo social com o interesse objetivo mais direto de transição até o socialismo"; (2) "a classe operária [...] sendo a única classe cujos interesses não se baseiam na opressão de outras classes, pode gerar as condições necessárias para liberar todas as pessoas através da luta por sua própria libertação"; (3) a "luta de classe deve ser o motor principal desta transformação emancipadora"; e (4) "a classe operária é a única força social com poder estratégico suficiente para permitir que se desenvolva em força revolucionária" (WOOD, 1998, p. 14-15, tradução nossa). 


\section{A proposta de Ellen Wood: sistematizar uma teoria de classes com base em Edward Palmer Thompson}

Ellen Wood defende que "a unidade das lutas econômicas e políticas é o que é capaz de tornar sinônimos democracia e socialismo" (WOOD, 2011b, p. 49). Sem isso, a democracia possível é a democracia liberal, portanto, formal e limitada aos imperativos da representação. Assim, para atingir tal unidade, três elementos devem ser destacados:

I. A divisão de trabalho entre classe e Estado significa que o Estado representa o "momento" coercitivo da dominação de classe no capitalismo, corporificado no monopólio mais especializado, exclusivo e centralizado de força social. O Estado, em última análise, é o ponto decisivo de concentração de todo poder na sociedade;

II. As lutas no plano da produção atuam no local da expropriação, mas permanecem incompletas, pois não se estendem até a sede do poder sobre o qual se apoia a propriedade capitalista, que detém o controle da produção e da apropriação; e

III. As batalhas puramente "políticas" em torno do poder de governar e dominar continuarão sem solução enquanto não implicarem, além das instituições do Estado, os poderes políticos que foram privatizados e transferidos para a esfera econômica.

A partir dessas considerações iniciais, entendemos que o capitalismo concentra a luta de classes no "ponto da produção", porque é somente no capitalismo que a organização da produção e apropriação coincidem tão completamente. A tendência é que a luta de classes seja localizada e particularizada: "a própria organização da produção capitalista resiste à unidade da classe operária que, supõe-se, o capitalismo deveria encorajar" (WOOD, 2011b, p. 48). Por isso, o desenvolvimento da consciência da classe operária e da sua organização deve ocorrer contra a força centrífuga da produção capitalista e da privatização das questões políticas.

Entretanto, devido à diferenciação entre o econômico e o político, a militância e a consciência política se tornam questões separadas. Ademais, o economicismo da classe operária em países desenvolvidos, visto como subdesenvolvimento da consciência de classe inclusive por socialistas, é, na verdade, o reflexo da mudança de arena e dos objetivos da luta política inerente à própria estrutura da produção capitalista - a produção capitalista tende a transformar em políticas as lutas econômicas.

A questão que se erige a partir dessas afirmações é que, para uma renovação do materialismo histórico, que reconheça essa separação do político e do econômico, faz-se necessária também uma nova teoria sobre a noção de classe. Uma noção que dê conta desse comportamento dinâmico das relações de produções e que seja adequada para pensar a luta de classes nesse contexto de separação da condição cívica em relação à condição de classe. É por essa razão que Ellen Wood reconhece na obra de Thompson uma concepção de classe adequada à renovação do materialismo histórico:

[...] o modo de análise de Thompson permite reconhecer o papel ativo da classe trabalhadora, com sua cultura e valores, em sua própria "formação". Este papel pode ser obscurecido por formulações que falam, por uma parte, do "agrupamento e transformação de objetivos da força de trabalho pela revolução industrial", e por outra - sequencialmente - "da subjetiva germinação de uma cultura de classe em resposta a ela" (WOOD, 1983, s/p., tradução nossa).

Há duas considerações contextuais iniciais sobre a produção de Thompson. O historiador britânico produz sua elaboração teórica sobre classe como marxista justamente no período de sua ruptura com o Partido Comunista. Sua produção, como membro do Grupo de Historiadores do Partido Comunista Britânico, é fortemente ancorada na análise histórica em contraste com as produções do Marxismo Ocidental. É a partir disto que, para muitos analistas, Thompson seja um "marxista heterodoxo". 
Thompson, em sua obra A Formação da Classe Operária Inglesa, pretende ressaltar o movimento de "autofazer-se" das classes sociais ao longo da história. Essa pretensão, segundo a tradutora do volume I, Denise Botman, é prejudicada pela tradução, pois “a palavra 'formação' perde em muito o conteúdo subjetivo e processual de 'making". Classe, para Thompson, não é uma estrutura ou categoria, mas "um fenômeno histórico, que unifica uma série de acontecimentos díspares e aparentemente desconectados, tanto na matéria-prima da experiência como na consciência [...] [é] algo que ocorre efetivamente (e cuja ocorrência pode ser demonstrada) nas relações humanas" (THOMPSON, 1987, p. 9).

Ao enfatizar que não enxerga classe apenas como uma "estrutura" ou "categoria" e que nem mesmo a "mais fina rede sociológica consegue oferecer um exemplar puro de classe", Thompson está chamando a atenção para o fato de que a classe "estava presente no seu próprio fazer-se [...] [como resultado de] experiências comuns (herdadas ou partilhadas)". Ou seja, a experiência de classe é determinada, em grande medida, pelas relações de produção. Enquanto a "consciência de classe é a forma como essas experiências são tratadas em termos culturais: encarnadas em tradições, sistemas de valores, ideias e formas institucionais" (THOMPSON, 1987, p. 9-10).

Assim sendo, Thompson não pretende "negar a existência da classe na ausência da consciência de classe". Ao contrário, ele buscou explicar como a atuação em formas de classe é pré-condição das formações completas e conscientes de classe. Portanto, antes de possuir instituições e valores "conscientemente definidos como classe", as pessoas atuam em formas de classe. Dito de outro modo, o historiador britânico fugiu da tautologia que "classe" é igual à "relação com os meios de produção" e explicou as consequências das relações sociais estruturadas em torno das classes sobre os agentes desprovidos de consciência de classe, que são "pré-condição" para a classe madura e conscientemente organizada. Além disto, demonstra que "a luta de classe precede a classe", pois o conflito e a luta nascem das relações de produção, enquanto as formações de classe dependem da experiência do conflito e da luta. Ainda, conflitos e lutas estruturados em "forma de classe" não ocorrem apenas em formações sociais onde as classes são conscientemente organizadas (WOOD, 1983, s/p., tradução nossa).

Para fazer sentido essa análise à luz do marxismo, é preciso repensar a metáfora do edifício para análise da "base" e da "superestrutura". Tal metáfora, segundo Ellen Wood, "gerou mais problemas do que soluções". Para justificar a necessidade de revê-la, Ellen Wood aponta que "embora o próprio Marx a tenha usado muito raramente e apenas nas formas mais aforísticas e alusivas, ela passou a suportar um peso teórico muito superior à sua limitada capacidade". O agravamento desse descompasso ocorre "pela tendência de Engels de usar uma linguagem que sugeria compartimentação de esferas ou 'níveis' fechados" e, principalmente, "com o estabelecimento das ortodoxias stalinistas que elevaram - ou reduziram - a metáfora à condição de primeiro princípio do dogma marxista-leninista”. Deste modo, tais "deformações das ideias histórico-materialistas originais de Marx fixaram os termos do debate marxista desde então” (WOOD, 2011b, p. 51).

Recorrendo a Perry Anderson, Ellen Wood afirma:

[...] a principal objeção feita por Thompson e outros contra a metáfora da base/superestrutura é o fato de a distinção analítica entre os vários "níveis" ou "casos" poder encorajar a ideia de que eles "existem substantivamente como objetos separados, fisicamente divisíveis uns dos outros no mundo real", criando uma confusão entre "procedimentos epistemológicos" e "categorias ontológicas" (WOOD, 2011b, p. 71).

Por isso, a historiadora e teórica política chama a atenção para a necessidade de repensar a base e a superestrutura para uma renovação do materialismo histórico, reconhecendo o esforço empreendido por E. P. Thompson:

Como Thompson sabe muito bem, 'interação mútua não chega a ser determinação'; e, tal como Marx, ele não tem intenção de fugir assim da questão da indeterminação. Sua formulação é apenas uma forma de levar a sério o entendimento de Marx sobre a 'base material' como algo que se corporifica na atividade prática humana, que, por mais que isso possa violar a sensibilidade dos marxistas 'científicos', exige de nós enfrentarmos o fato de ser a atividade de produção material uma atividade consciente (WOOD, 2011b, p. 65). 
Ou seja, há uma relação dialética entre a base e a superestrutura. Porém, essa relação dialética não indica uma indeterminação, pois a base material determina em última instância a atividade prática humana. Porém, a atividade de produção material, que está na base, é uma atividade na qual os agentes são dotados de consciência. Consciência esta que não se encontra, a priori, pronta e acabada, mas está sempre permeada dos elementos superestruturais (política, religião, ideologia etc.). Portanto, o que se coloca para Thompson é que o homem, como sujeito cognoscente, reflete a partir da sua experiência proporcionada pela situação de classe. Feita essa consideração, é preciso compreender a refutação da concepção de classe de duas correntes científicas distintas.

Em suma, Thompson entende que no próprio marxismo há uma forte tendência de tratar classe - diferente do significado original em Marx - como "coisa". Esse erro faz com que muitos seguidores do marxismo tomem o conceito como "tendo uma existência real, capaz de ser definida quase matematicamente - uma quantidade de homens que se encontra numa certa proporção com os meios de produção". Partindo desse erro, deduz-se uma dada consciência de classe que o proletariado "deveria" ter e que há uma superestrutura cultural que provoca "distorções culturais" e "defasagens", levando a formulações de teorias substitutivas em que aparecem "o partido, a seita ou o teórico que desvenda a consciência de classe, não como ela é, mas como deveria ser” (THOMPSON, 1987, p. 10).

$\mathrm{Na}$ outra, "como a tosca noção de classe atribuída a Marx pode ser criticada sem dificuldade, assume-se que qualquer noção de classe é uma construção teórica pejorativa, imposta às evidências" (THOMPSON, 1987, p. 10-11). Em reação, surge outra concepção de classe entre os pós-marxistas. Talcott Parsons e Ralph Dahrendorf, por exemplo, partem de uma tese que classe pode ser definida como parte da estrutura social.

Entretanto, eles tendem a ver a consciência de classe como "algo daninho, inventado por intelectuais deslocados, visto que tudo o que perturba a coexistência harmoniosa de grupos que desempenham diferentes 'papéis sociais' deve ser lamentado" (THOMPSON, 1987, p. 11). Para eles, o problema está em como fazer com que os indivíduos aceitem o seu papel social. Já as análises de Laclau, Hindess, Hirst e Jones colocam as divisões ideológicas ou "discursivas" como oposições fundamentais, retirando a política e a luta de classes do lugar central (WOOD, 1998).

Refutando tais análises, o historiador britânico desenvolve no volume 2 - A maldição de Adão, da obra Formação da classe operária inglesa, uma análise sobre os grupos de trabalhadores cuja experiência parece destacar a consciência da classe operária. Thompson destaca o papel dos trabalhadores rurais, artesãos urbanos e tecelões artesanais nesse processo do "fazer-se" da classe operária, uma vez que mineiros e metalúrgicos não exerceram inteiramente sua influência até o final do século XIX. Segundo ele,

[...] a ênfase excessiva sobre o caráter inovador das tecelagens pode levar ao menosprezo da continuidade de tradições políticas e culturais na formação das comunidades da classe operária. Os operários, longe de serem os 'filhos primogênitos da Revolução industrial', tiveram nascimento tardio. Muito de suas ideias e formas de organização foram antecipadas por trabalhadores domésticos [...] É discutível se os operários exceto nos distritos algodoeiros - 'formaram o núcleo do Movimento Trabalhista' antes do final da década de 1840 (THOMPSON, p. 2012, 15).

O autor localiza a formação da classe operária como o fato relevante do período 1790-1830:

Isso é revelado, em primeiro lugar, no crescimento da consciência de classe: a consciência de uma identidade de interesses entre todos esses diversos grupos de trabalhadores contra os interesses de outras classes. E, em segundo lugar, no crescimento das formas correspondentes de organização política e industrial. Por volta de 1832, havia instituições da classe operária solidamente fundadas e autoconscientes - sindicatos, sociedades de auxílio mútuo, movimentos religiosos e educativos, organizações políticas, periódicos -, além das tradições intelectuais, padrões comunitários e da estrutura da sensibilidade da classe operária (THOMPSON, p. 2012, 17). 
Portanto, para análise da classe, tratá-la como "coisa" ou como locus na estratificação social "parte da estrutura social" - é insuficiente, pois:

A formação da classe operária é um fato tanto da história política e cultural, quanto da econômica. Ela não foi gerada espontaneamente pelo sistema fabril. Nem devemos imaginar alguma força exterior - a 'Revolução Industrial' - atuando sobre algum material bruto, indiferenciado e indefinível de humanidade, transformando-o em seu outro extremo, uma 'vigorosa raça de seres' [...] A classe operária formou a si própria tanto quanto foi formada (THOMPSON, p. 2012, 17-18).

Entendemos que, conforme defende Thompson, apenas identificar a existência de grupos que compõem a estrutura social em um dado momento da história diz pouco ou quase nada das dinâmicas internas às relações entre produtores e apropriadores. Por isso, nas palavras de Thompson:

[...] a questão é como o indivíduo veio a ocupar esse 'papel social' e como a organização social específica (com seus direitos de propriedade e estrutura de autoridade) aí chegou. Estas questões são históricas. Se detemos a história num determinado ponto, não há classes, mas simplesmente uma multidão de indivíduos com emaranhado de experiências. Mas se examinarmos esses homens durante um período adequado de mudanças sociais, observaremos padrões em suas relações, suas ideias e instituições (THOMPSON, p. 1987, 11-12).

Ellen Wood, sustentando a visão de Thompson sobre essa questão, afirma ser necessário “demonstrar como a estruturação da sociedade nas 'formas de classes' realmente afeta as relações sociais e os processos históricos", ou seja, é necessário "ter uma concepção de classe que nos convide a descobrir como as situações objetivas de classe formam nossa realidade". Por isto, aprofundar esse debate entre Thompson e outros marxistas implica reconhecer e problematizar que não é suficiente "afirmar e reafirmar a proposição tautológica de que 'classe é igual à relação com os meios de produção" (WOOD, 2011b, p. 78).

E. P Thompson propõe uma interpretação sobre as classes baseadas no binômio: relação e processo. Antes de prosseguir na explicação do que significa tal binômio, é fundamental considerar que “nem Marx, nem Thompson, nem ninguém desenvolveu um vocabulário teórico ‘rigoroso' para expressar os efeitos das condições materiais sobre seres ativos e conscientes". Isso ajuda a compreender o grau de dissenso que há em relação a alguns conceitos usados por Thompson, em especial, o conceito de experiência, que, por vezes, é visto como expressão de seu "subjetivismo" e "idealismo" (WOOD, 1983, s/p., tradução nossa).

Dito isto, passemos a explicar o binômio relação e processo. Thompson, como já afirmamos, não busca localizar as classes meramente a partir de posições estruturais. A localização é feita por meio de relações. Os processos de formação de classe são impulsionados pelas relações de exploração, conflito e luta (WOOD, 1983).

Pensar a classe como relação significa observar dois tipos de relação existentes: (1) entre as classes e (2) entre os membros de uma mesma classe. Assim, opõe-se, claramente, a ideia de classe como mera categoria de estratificação. Nessa linha de argumentação de Thompson, as "relações de produção" fundamentam as "relações de classe", como qualquer teoria materialista afirmaria. Porém, as relações de produção são aquelas estabelecidas por pessoas unidas pelo processo de produção e os antagonismos entre produtores diretos e apropriadores do excedente. Cumpre advertir que "as relações de classe não são redutíveis a relações de produção": nem todos os membros potenciais das classes históricas são vinculados diretamente pelo processo de produção ou pelo processo de apropriação - são as pessoas agrupadas em classes e não as classes que produzem ou apropriam (WOOD, 1983, s/p., tradução nossa). Em outros termos:

A "classe" não se refere simplesmente aos trabalhadores agrupados em uma unidade de produção e opostos a um explorador comum em uma unidade de apropriação. A classe implica uma conexão que se estende para além do processo de produção imediato e do nexo imediato de extração, uma conexão que 
se projeta através das unidades de produção e apropriação particulares. As conexões e oposições contidas no processo de produção são a base da classe, mas a relação entre pessoas que ocupam posições similares nas relações de produção não está diretamente relacionada ao processo de produção e apropriação (WOOD, 1983, s/p., tradução nossa).

A formação de classe não é facilmente explicável sem recorrer ao termo "experiência". Essa categoria, à primeira vista, pode complicar a compreensão, mas isto ocorre justamente porque são complexos os mecanismos que fazem as relações de produção dar origem à classe. Entretanto, isso não significa "negar a pressão determinante" das relações de produção. Em suma, experiência é o termo cujo significado afirma que as "estruturas objetivas" impactam na vida das pessoas e para compreender "o que estas estruturas fazem", como atuam e como as pessoas reagem em relação a isso é o papel de historiadores e sociólogos (WOOD, 1983, s.p., tradução nossa). Desenvolveremos, nos próximos subtítulos, as críticas e o detalhamento de como Thompson confere centralidade à experiência.

Além disto, Thompson considera fundamental o reconhecimento da noção de classe como um processo estruturado, o que significa afirmar que "há uma base estrutural na formação de classe", mas é preciso procurar nas relações antagônicas de produção as formas particulares em que as pressões estruturais atuam na formação das classes. Essa busca deverá ser realizada empiricamente por meio de análise histórica e sociológica. Em reação a essa proposição, Thompson foi acusado de equiparar "a classe com a consciência de classe". $\mathrm{Na}$ verdade, o historiador britânico compreende que "as formas de consciência são moldadas em diversas formas pelas 'pressões determinantes' de situações objetivas de classe", mesmo quando ainda não está expressa "uma identidade de classe autoconsciente e ativa". Entre uma situação objetiva de classe, sem identidade autoconsciente e ativa, e uma formação visível, consciente e ativa de classe está o processo histórico (WOOD, 1983, s/p., tradução nossa).

\section{Considerações finais}

O empreendimento de Ellen Wood se deu em meio a um "marxismo em recessão", que pode ser percebido, segundo Hobsbawm, pelos seguintes sintomas: (1) "a crise dos partidos comunistas europeus fora do poder e dos partidos e governos socialistas estava mais do que evidente"; (2) "mesmo fora da política, o marxismo já estava em regressão entre os intelectuais, mas isso só se tornou óbvio na década de 1980"; (3) apesar de historicamente periférico nos estudos acadêmicos em economia, a partir de 1974, e o Nobel de Economia é um sintoma, torna-se possível verificar "uma rejeição do keynesianismo e de outras teorias intervencionistas em favor de uma volta ao laissez-faire intransigente. Só no fim dos anos 1990 começaram a aparecer rachaduras nesse consenso predominante"; (4) nas ciências sociais e humanas o marxismo vai perdendo o papel central que ocupava, inclusive, metodologicamente; e (5) na própria antiga esquerda radical - desde a esquerda radical anterior a 1914 até esquerda radical dos anos 1960 "inclinada ao ativismo à outrance" - era perceptível um "recuo em relação ao marxismo" (HOBSBAWM, 2011, p. 349-353).

Em reação, Ellen Wood propõe a renovação do materialismo histórico tendo a Democracia Substantiva como o norte, como a organização político-social capaz de enfrentar a exploração de classe e de tornar inócuos os fundamentos que utilizam as identidades sociais histórica e culturalmente discriminadas como possibilidades de ampliar a capacidade de apropriação da classe dominante. Ela entende que a luta pela democracia permite a unificação das diversas manifestações anticapitalistas. Nesse ínterim, as liberdades civis básicas são indispensáveis, mas, além disso, é preciso recuperar integralmente a concepção de governo pelo povo ou pelo poder do povo. 
Isto implica que o demos, o homem comum, tenha condições de enfrentar a dominação de classe. Qualquer projeto que se intitular anticapitalista, mas que acredita na reforma da democracia e sua compatibilidade com o capitalismo, é "menos anticapitalista que antineoliberal ou antiglobalização". Afinal, como "governo de classe pelo capital" não existe - e nem é possível - "um capitalismo governado pelo poder popular", pois os imperativos do mercado têm primazia sobre a vontade e as necessidades do povo (WOOD, 2011b, p. 7-8).

Para melhor definir, a autora entende que a identificação de democracia com liberalismo só é possível na vigência das "relações sociais específicas do capitalismo", ou seja, quando se faz um exame histórico, é possível identificar a democracia em diversos contextos históricos específicos. Porém, na vigência do capitalismo há uma redefinição introduzida pela Constituição dos Estados Unidos, que busca no governo representativo com raízes na República Romana e no senhorio medieval. A partir dessa redefinição, a noção de democracia se desenvolve atrelada à de representação até chegar "à concepção moderna de democracia" (WOOD, 2011b, p. 23).

É nesse desenvolvimento de uma democracia formal, que identifica democracia e liberalismo, que ocorre um paradoxo: as "relações sociais específicas do capitalismo" resulta "tanto no avanço da democracia quanto na sua estrita inibição". Sendo assim, "o maior desafio ao capitalismo seria a extensão da democracia além de seus atuais limites extremamente reduzidos” (WOOD, 2011b, p. 23).

Ampliar os limites da democracia para além dos atuais significa conceder aos produtores a capacidade de autodeterminação da produção, o que representa a própria condenação do capitalismo, uma vez que, para sua existência, conservação e reprodução, os poderes políticos não alteram, substancialmente, o seguinte dispositivo do capitalismo: a "propriedade privada absoluta para o capitalista, e seu controle sobre a produção e a apropriação.” (WOOD, 2011b, p. 28).

No intento de argumentar pela Democracia Substantiva como regulador econômico, em $A$ Democracia contra o capitalismo, Ellen Wood entende que o "projeto crítico" é a compreensão do capitalismo como "um sistema de relações sociais; e isso significa repensar algumas das formas como foram concebidos os conceitos principais do materialismo histórico - forças e relações de produção, classe, base e superestrutura, etc.” (WOOD, 2011b, p. 21, grifo meu). Em termos mais diretos:

É necessário, em primeiro lugar, não ter ilusões acerca do significado e dos efeitos da democracia no capitalismo. Isso representa não somente a compreensão dos limites da democracia capitalista, o fato de que até mesmo um Estado capitalista democrático pode ser restringido pelas exigências de acumulação do capital, e o fato de que a democracia liberal deixa essencialmente intacta a exploração capitalista, mas também, e ainda mais particularmente, a desvalorização da democracia (WOOD, 2011b, p. 233, grifos da autora).

A Democracia Substantiva funciona como "um regulador econômico, o mecanismo acionador da economia". Afinal, não basta a "reapropriação dos meios de produção pelos produtores [...] [quando a] posse permanece dependente do mercado e dos velhos imperativos". Uma democracia que garanta, de fato, "a liberdade de livre associação (sic)" e, por consequência, "a emancipação de coações 'econômicas'." (WOOD, 2011b, p. 248). Porém, para atingir este objetivo, é preciso resgatar a centralidade da luta de classes.

Em coerência, Ellen Wood propõe a compreensão da classe como relação e processo como caminho necessário para superar os elementos particularistas da luta social e política. Afinal, não se enfrenta a separação entre o político e econômico sem a unificação na experiência e na consciência de acontecimentos díspares e aparentemente desconectados ou, dito de outro modo, sem que a classe seja "algo que ocorre efetivamente (e cuja ocorrência possa ser demonstrada) nas relações humanas" (THOMPSON, 1987, p. 9). 


\section{Referências}

BRASIL. Instituto de Pesquisa Econômica Aplicada (IPEA). Carta de Conjuntura, 26 mar. 2015. Disponível em: http://www.ipea.gov.br/agencia/images/stories/PDFs/conjuntura/150430 cc abr 2015 economia mundial.pdf. Acesso em: 09 de set. 2018.

CARDOSO, Juliane Helanski; SILVA, Vania Sandeleia Vz da; NERES, Geraldo Magella. Como Estudar Teoria Política: Textualismo, Contextualismo Linguístico e Contextualismo Social. In: SIMPÓSIO PARANAENSE DE CIÊNCIAS SOCIAIS, V., 18 a 20 maio 2016. Anais... Cascavel, PR: UNIOESTE, 2016, p. 63-85. Disponível em: < http://200.201.88.178/simposiocienciassociais/anais.php>.

DRIBINS, Leo. The History of the Jewish Community in Latvia a brief chronological survey. In: DRIBINS, Leo et al. The Jewish Community of Latvia: History, Tragedy, Revival. Latvia. Ministry of Foreign Affairs of the Republic of Latvia, 30 out. 2014. Disponível em: <https://web.archive.org/web/20141016074036/http://www.mfa.gov.lv/en/ministry/publications/4 299/\#1-34>. Acesso em: 14 nov. 2018.

FERNANDES, Florestan. Marx, Engels e Lênin: história em processo. São Paulo: Expressão Popular, 2012.

HARVEY, David. A Condição Pós-Moderna: Uma Pesquisa sobre as Origens da Mudança Cultural. 23. ed. São Paulo: Edições Loyola, 2012.

HOBSBAWM, Eric. Como mudar o mundo: Marx e o marxismo, 1840-2011. São Paulo: Companhia das Letras, 2011.

MARX, Karl; ENGELS, Friedrich. Manifesto Comunista. São Paulo: Boitempo, 2007.

MCNALLY, David. Ellen Meiksins Wood obituary. The Guardian, Londres, 10 fev. 2016. Disponível em: < https://www.theguardian.com/books/2016/feb/10/ellen-meiksins-wood-obituary $>$.

SANTANA, Marco Aurélio; RAMALHO, José Ricardo. Sociologia do Trabalho no Mundo Contemporâneo. 3. ed. Rio de Janeiro: Jorge Zahar, 2010.

SARTELLI, Eduardo. La Niebla. In: WOOD, Ellen. ¿Una Política sin Clases? El post-marxismo y su legado. Buenos Aires: RyR, 2013. p. 7-24.

SNEIDERE, Irene. The First Soviet Ocupation Period in Latvia 1940-1941. In: Institute of the History of Latvia. The hidden and forbidden: History of Latvia under Soviet and Nazi Occupations 1940-1991. Riga: University of Latvia, 2005. Disponível em: < https://web.archive.org/web/20150721112533/ http://www.president.lv/images/modules/items/PDF/item 1624 Vesturnieku komisijas raksti_14_s ejums.pdf $>$. Acesso em: 16 nov. 2018.

THOMPSON, E. P. A Formação da Classe Operária Inglesa: volume I: A árvore da liberdade. Rio de Janeiro: Paz e Terra, 1987.

A Formação da Classe Operária Inglesa: volume II: A maldição de Adão. 2. ed. Rio de Janeiro: Paz e Terra, 2012.

WOOD, Ellen Meiksins. El concepto de clase en E. P. Thompson. Cuadernos Políticos [online], n. 36, p. 87-105, abr./jun. 1983. Disponível em: < http://www.cuadernospoliticos.unam.mx/cuadernos/ contenido/CP.36/CP.36.9.EllenMeiksinsWood.pdf> . Acesso em: 15 nov. 2018.

. The Retreat from Class: a new 'true' Socialism. London: Verso, 1998.

. De ciudadanos a señores feudales: História social del pensamiento político desde la Antigüedad a la Edad Media. Barcelona: Paidós, 2011a.

Democracia contra o capitalismo: a renovação do materialismo histórico. São Paulo: Boitempo, 2011b.

WOOD, Neal. Reflections on Political Theory: a voice of reason from the past. New York: Palgrave, 2002. 